Part of Journal of Research of the National Bureau of Standards, Volume 22, March 1939

\title{
SEPARATION OF HYDROCARBONS OF HIGH MOLECULAR WEIGHT BY ADSORPTION ON SILICA GEL ${ }^{1}$
}

\author{
By Charles B. Willingham ${ }^{2}$
}

\section{ABSTRACT}

Data are presented on the separation of different types of hydrocarbons of high molecular weight by adsorption on silica gel. A sharp separation of 5-(7tetrahydronaphthyl)-docosane from 5-(2-decahydronaphthyl)-docosane, and $n$ dotriacontane from 1-( $p$-diphenyl)-octadecane was obtained. Some separation of 1-( $p$-diphenyl)-octadecane from 5-(7-tetrahydronaphthyl)-docosane was found, but the separation was not as sharp as with the two preceding mixtures. No separation of a mixture of $n$-dotriacontane and 5-(2-decahydronaphthyl)-docosane was found.

The capacity of $20 \mathrm{~g}$ of silica gel to adsorb preferentially the more aromatic components of these mixtures was found to be $1.8,3.3$, and $0.8 \mathrm{~g}$, respectively, for the first three mixtures listed above.

\section{CONTENTS}

I. Introduction

II. Apparatus and material _... 321

III. Procedure

IV. Experimental results $\ldots \ldots \ldots 323$

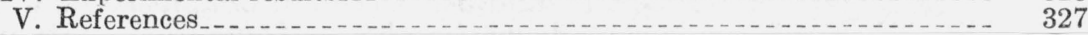

\section{INTRODUCTION}

Preferential adsorption by silica gel has been used for several years for separating mixtures of hydrocarbons of both the gasoline [1] ${ }^{3}$ and lubricating oil [2] fractions of petroleum. The study made by Mair and White [3] showed that, for hydrocarbons similar to those occurring in the gasoline fraction of petroleum $\left(\mathrm{C}_{5}\right.$ to $\left.\mathrm{C}_{10}\right)$, adsorption with silica gel is effective in removing completely small amounts of aromatic hydrocarbons from their mixtures with paraffin and naphthene hydrocarbons, and further, gave information concerning the efficiency and capacity of the gel for such separation. However, as no data have heretofore been reported concerning the effectiveness of silica gel for separating hydrocarbons of high molecular weight, it is the purpose of the present note to report such information.

\section{APPARATUS AND MATERIAL}

The apparatus used was essentially the same as that described by Mair and White [3], except that both the tube containing the silica

\footnotetext{
1 Financial assistance has been received from the research fund of the American Petroleum Institute. This work is part of Project 6, The Separation, Identification, and Determination of the Constituents of Petroleum.

2Research Associate at the National Bureau of Standards, representing the American Petroleum Institute.

${ }^{3}$ Numbers in brackets indicate the literature references at the end of this paper.
} 
gel and the receiver were equipped with a heating jacket, as shown in figure 1. Because of the high melting point of some of the hydrocarbons, several of the experiments were performed at about $100^{\circ} \mathrm{C}$, and for the same reason, the refractive indices, used to mark the extent of the separation (as illustrated in fig. 2), were determined at $80^{\circ} \mathrm{C}$.

The silica gel used was marked " $150-\mathrm{F}-850$ " (40 to 200 mesh). ${ }^{4}$

Three of the synthetic hydrocarbons

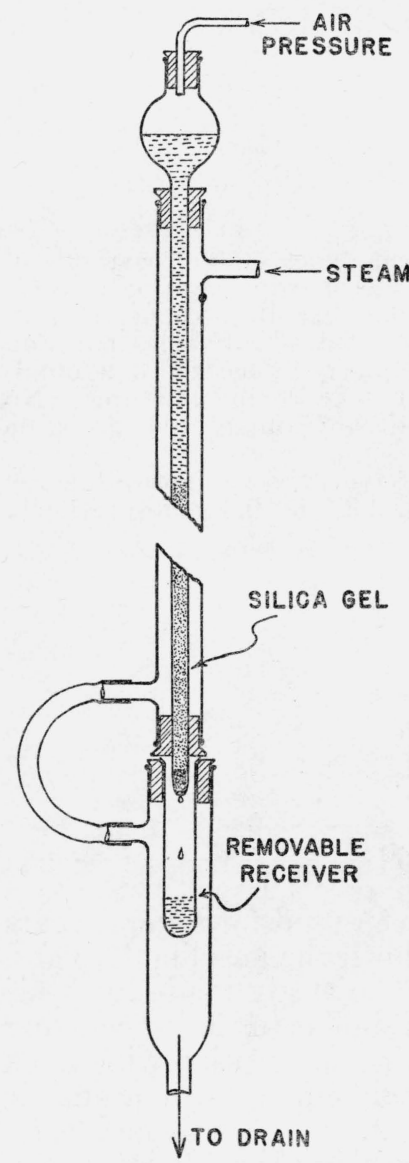

FIGURE 1.-Apparatus for filtering hydrocarbons of high molecular weight through silica gel.

experiments). components were then melted by placing the flask on the steam bath, and thoroughly agitated to insure homogeneity. After the refractive index had been determined, the mixture was transferred to the filtering tube and allowed to filter, under an air pressure of about $4 \mathrm{lb}$./in. ${ }^{2}$ through $50 \mathrm{~cm}$ (approximately $20 \mathrm{~g}$ ) of loosely packed gel.

In all of the experiments except No. 1 , the filtering tube and receiver were kept at approximately $100^{\circ} \mathrm{C}$ by passing steam through

\footnotetext{
4 This was purchased from the Davison Chemical Corporation, Silica Gel Division, Baltimore, Md.
} 
the jacket. A small gas flame from a bunsen burner was used, as needed, to keep the material in the upper bulb liquid. The filtrate was collected in a number ( 7 to 9 ) of small fractions, and the refractive index of each was determined.

The previously used technique [3] of displacing the adsorbed material from the gel with water could not be used in the present experiments because of the higher temperature. Instead, toluene, which boils at $110^{\circ} \mathrm{C}$ and is highly adsorbed by silica gel, was passed through the column to displace the adsorbed hydrocarbons of high molecular weight, which were thus obtained in solution with the excess toluene. The bulk of the toluene was subsequently separated from the wanted hydrocarbons by simple distillation, with the last traces of toluene being removed at $120^{\circ}$ to $130^{\circ} \mathrm{C}$ by sweeping with a small stream of carbon dioxide.

\section{EXPERIMENTAL RESULTS}

Experiment 1 (see table 1), performed at about $25^{\circ} \mathrm{C}$ (room temperature), shows the recovery of substantially pure 5-(7-decahydronaphthyl)-docosane, a naphthene or cycloparaffin hydrocarbon, from its mixture with the corresponding aromatic hydrocarbon. The separation was sharp, and the capacity of the gel was found to be $1.8 \mathrm{~g}$ of aromatic hydrocarbon adsorbed by $20 \mathrm{~g}$ of gel. ${ }^{5}$

\footnotetext{
$\checkmark$ This capacity does not differ greatly from that reported by Mair and White [3] for hydrocarbons of low molecular weight; namely, $5.6 \mathrm{~g}$ of 0 -xylene adsorbed by $50 \mathrm{~g}$ of gel from a 10-percent solution of it with $n$-nonane, and $5.2 \mathrm{~g}$ of toluene adsorbed by $50 \mathrm{~g}$ of gel from a 10-percent solution of it with $n$-heptane.
} 
TABLE 1.-Experimental results

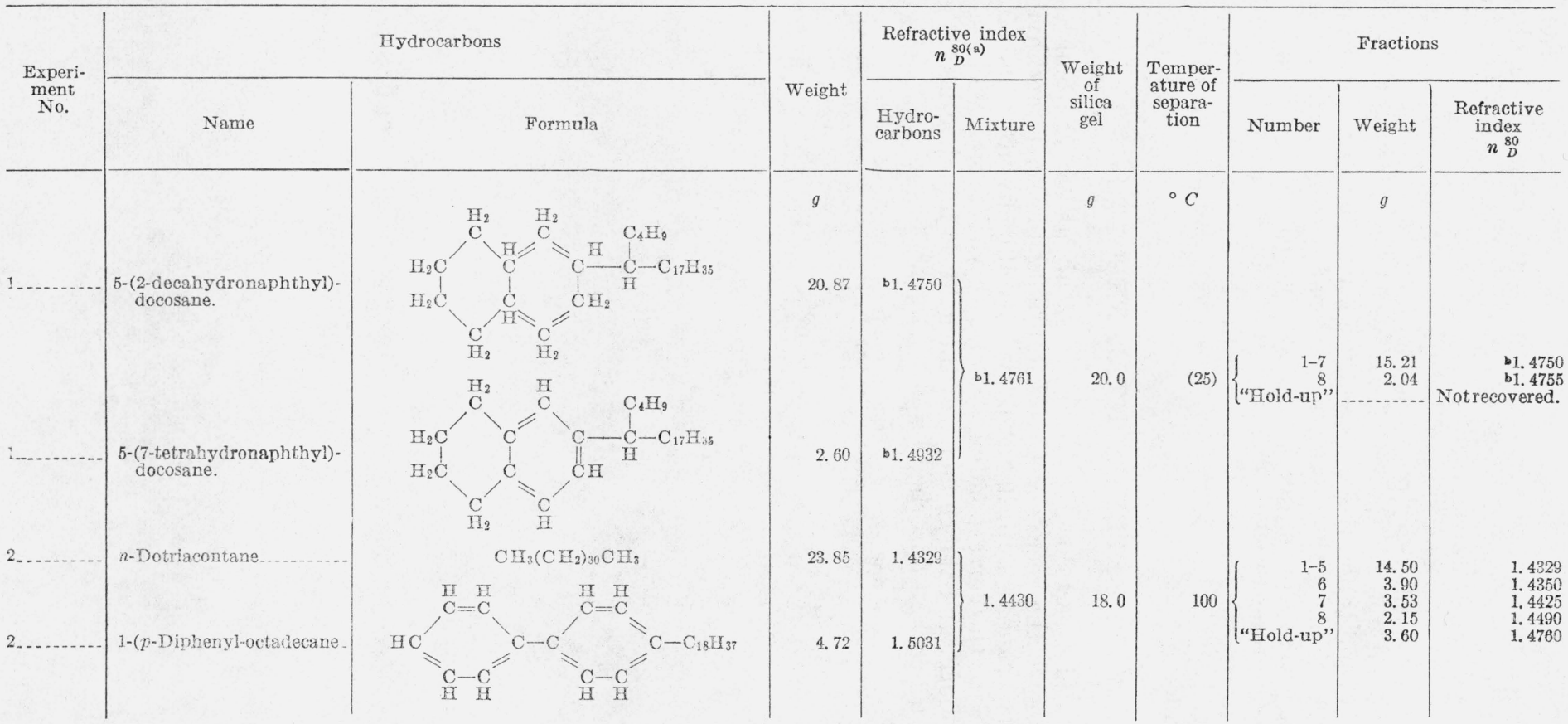




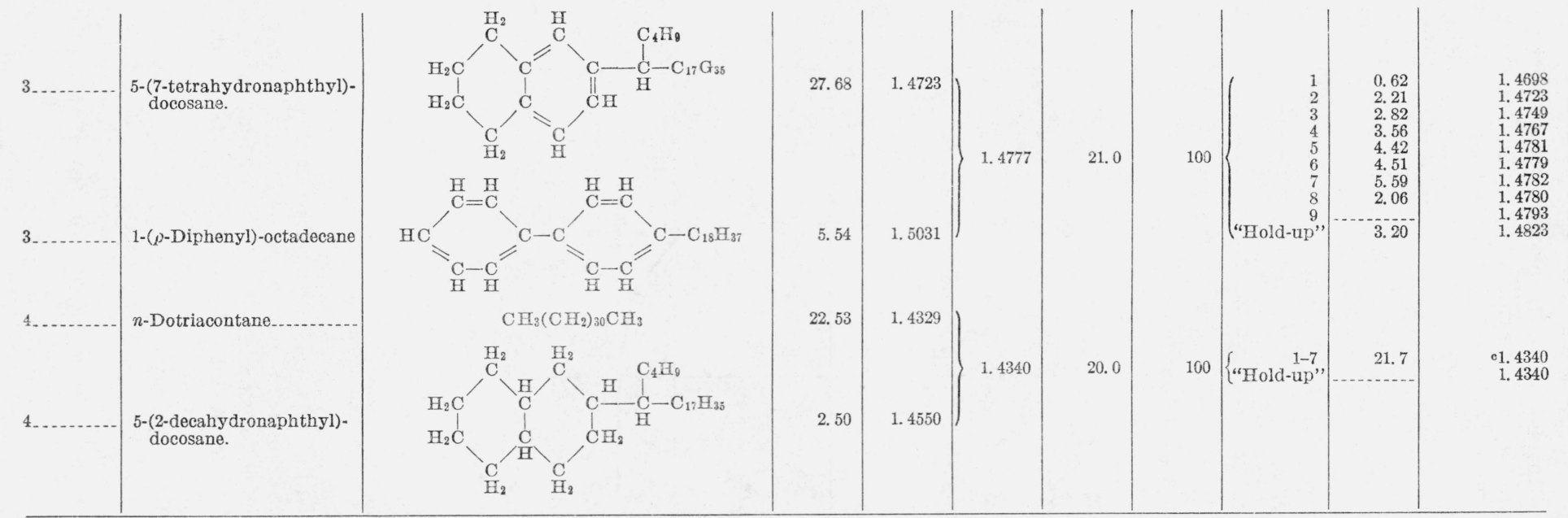

a Because of the difficulty experienced in maintaining this high temperature, the refractive indices reported here are considered accurate only to \pm 0.0002.

b These refractive indices were determined at $25^{\circ} \mathrm{C}$. 
A sharp separation was obtaned also in experiment 2, where substantially pure $n$-dotriacontane, a paraffin hydrocarbon, was recovered from its mixture with the aromatic hydrocarbon 1- $p$ diphenyl)-octadecane. A graphical representation of this separation is shown in figure 2. In this experiment, the capacity of the gel was much greater than in experiment 1 , being $3.3 \mathrm{~g}$ of aromatic hydrocarbon adsorbed by $20 \mathrm{~g}$ of gel from a solution containing 16.5 percent of the aromatic hydrocarbon.

Experiment 3 was performed with a mixture of 5-(7-tetrahydronaphthyl)-docosane which contains 1 aromatic ring, and 1-( $p$-di-

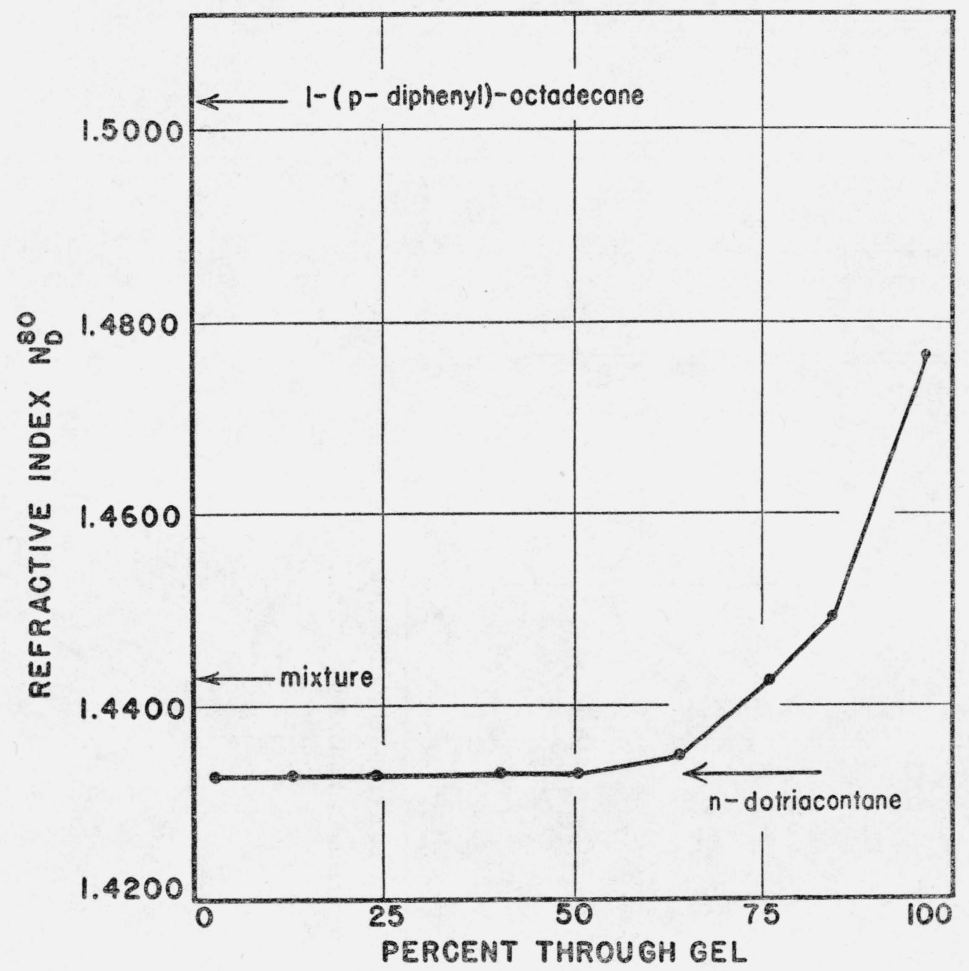

FigURE 2.-Plot showing the separation of a mixture of $23.85 \mathrm{~g}$ of $n$-dotriacontane and 4.72 $\mathrm{g}$ of 1 -(p-diphenyl)-octadecane.

The scale of ordinates gives the refractive index of the various fractions of the filtrate, and the scale of abscissas gives the percentage of material passed through the gel.

phenyl)-octadecane which contains 2 aromatic rings. It will be noted that a small amount $(0.62 \mathrm{~g})$ of material was obtained with a lower refractive index than that of the original 5-(7-tetrahydronaphthyl)docosane. This small amount of material with lower refractive index was obtained because the 5-(7-tetrahydronaphthyl)-docosane, as already pointed out, was itself slightly fractionated on passage through gel. The remaining fractions show some separation of the compound with 1 aromatic ring from that with 2 aromatic rings, though the separation was not as sharp as that of nonaromatic from aromatic 
hydrocarbons. Only $0.8 \mathrm{~g}$ of 1-( $p$-diphenyl)-octadecane was preferentially adsorbed from the mixture by $20 \mathrm{~g}$ of gel.

In experiment 4 it was found that substantially no separation occurred when a 9-to-1 mixture of the paraffin hydrocarbon, $n$-dotriacontane, with 5-(2-decahydronaphthyl)-docosane, which contains 2 naphthene rings (condensed), was filtered through silica gel under the same conditions as in the other experiments.

The author is grateful to B. J. Mair and F. D. Rossini for their suggestions and guidance, and to M. M. Haring, of the University of Maryland, for his interest in the problem.

\section{REFERENCES}

[1] F. W. Rose, Jr. and J. D. White, J. Research NBS 15, 151 (1935).

[2] B. J. Mair, S. T. Schicktanz, and F. W. Rose, Jr., J. Research NBS 15, 557 (1935).

[3] B. J. Mair and J. D. White, J. Research NBS 15, 51 (1935).

[4] L. A. Mikeska, Ind. Eng. Chem. 28, 970 (1935).

[5] Y. Delcourt, Bul. soc. chim. Belg. 40, 285 (1931).

Washington, January 9, 1939. 